\title{
Comparison between Citral and Pompia Essential Oil Loaded in Phospholipid Vesicles for the Treatment of Skin and Mucosal Infections
}

\author{
Iris Usach ${ }^{1}{ }^{(}$, Elisabetta Margarucci ${ }^{1,2}$, Maria Letizia Manca ${ }^{2}{ }^{(}$, Carla Caddeo $^{2}$, Matteo Aroffu $^{2}$, \\ Giacomo L. Petretto ${ }^{3}{ }^{\circ}$, Maria Manconi ${ }^{2} \mathbb{D}$ and José-Esteban Peris ${ }^{1, *}$ \\ 1 Department of Pharmacy, Pharmaceutical Technology and Parasitology, University of Valencia, Avda. V. \\ Andrés Estellés, s/n Burjassot, Valencia 46100, Spain; iris.usach@uv.es (I.U.); \\ elisabetta.margarucci@hotmail.it (E.M.) \\ 2 Department of Scienze della Vita e dell'Ambiente, University of Cagliari, Via Ospedale 72, Cagliari 09124, \\ Italy; mlmanca@unica.it (M.L.M.); caddeoc@unica.it (C.C.); matteo.aroffu@gmail.com (M.A.); \\ manconi@unica.it (M.M.) \\ 3 Department of Chemistry and Pharmacy, University of Sassari, Sassari 07100, Italy; gpetretto@uniss.it \\ * Correspondence: jose.e.peris@uv.es; Tel.: +34-963-543-353; Fax: +34-963-544-911
}

Received: 16 January 2020; Accepted: 5 February 2020; Published: 7 February 2020

\begin{abstract}
Citrus species extracts are well known sources of bio-functional compounds with health-promoting effects. In particular, essential oils are known for their antibacterial activity due to the high content of terpenes. In this work, the steam-distilled essential oil from the leaves of Citrus limon var. pompia was loaded in phospholipid vesicles. The physico-chemical characteristics of the essential oil loaded vesicles were compared with those of vesicles that were loaded with citral, which is one of the most abundant terpenes of Citrus essential oils. The biocompatibility of the vesicles was assessed in vitro in human keratinocytes. Furthermore, the antimicrobial activity of the vesicles was tested while using different bacterial strains and a yeast: Escherichia coli, Pseudomonas aeruginosa, Staphylococcus aureus, and Candida albicans, respectively. The vesicles were small in size ( 140 nm), slightly polydispersed (PI 0.31), highly negatively charged $(\sim-73 \mathrm{mV})$, and able to incorporate high amounts of essential oil or citral (E\% 86\%). Pompia essential oil and citral exhibited antimicrobial activity against all of the assayed microorganisms, with $P$. aeruginosa being the least sensitive. Citral was slightly more effective than pompia essential oil against E. coli, S. aureus, and C. albicans. The incorporation of citral in vesicles improved its antifungal activity against $C$. albicans.
\end{abstract}

Keywords: liposomes; pompia essential oil; citral; bacteria; yeast

\section{Introduction}

Citrus limon (L.) Osbeck var. pompia Camarda, which is also known as Citrus monstruosa, of the Rutaceae family [1], is an ancient endemic cultivar only grown in some warm areas of the north-eastern Sardinia (Italy) [2,3]. It is probably a hybrid species derived from citron and lemon that produces irregularly shaped, yellow fruits that are characterized by a low juice content and a reduced level of sugar [4]. An essential oil with antioxidant and antimicrobial activities can be obtained from pompia leaves. Limonene and citral (3,7-dimethyl-2,6-octadienal), which is a mixture of two isomeric acyclic monoterpene aldehydes, geranial (trans-citral or citral A) and neral (cis-citral or citral B), are the main components of pompia essential oil [3]. Citral, as well as essential oils containing citral and other terpenes, have been widely used in traditional medicine for the treatment of different infections, given their antimicrobial activity [5,6]. Recently, Zhang et al. (2020) [7] studied the antibacterial activity of seven essential oils that were obtained from Litsea cubeba, Rosemary, Citronella, Lavander, Spikenard, 
Bamboo leaf, and Vitex negundo. The most active oil against a food-derived strain (Stenotrophomonas maltophilia) was found to be Litsea cubeba oil. Such activity has been linked to the action of citral, which was the main component of the oil. The antibacterial activity of citral-containing essential oils is well documented in the literature, being in line with these findings [8,9].

The use of natural compounds is often limited because of their volatility and poor stability, despite the potential as therapeutic agents [10]. The incorporation in nanocarriers represents a suitable approach for overcoming these limitations. Liposomes are considered to be one of the most versatile nanocarrier systems capable of delivering both hydrophilic and lipophilic compounds. They offer several advantages as drug delivery systems, including high biocompatibility, self-assembly properties, the ability to carry large amounts of the payload, and a wide range of physico-chemical properties that can be modified in favour of their biological characteristics [11-14]. In previous studies, different essential oils were loaded in liposomes or modified liposomes to enhance their activities. For instance, cinnamon oil has been incorporated in soy lecithin, cholesterol liposomes to improve the antimicrobial activity [15]; thymus essential oil has been formulated in liposomes, glycerosomes, and Penetration Enhacer-containing Vesicles (PEVs) to enhance their antioxidant activity [16]; Salvia tribola and Rosmarinus officinalis essential oils have been loaded in liposomes, showing significant antioxidant, anti-inflammatory, and antibacterial activities, especially against Klebsiella pneumoniae [17].

In the present study, liposomes containing pompia essential oil or raw citral were prepared by direct sonication while using soy phosphatidylcholine. The physico-chemical properties of the obtained vesicles were evaluated, and their biocompatibility was assessed in vitro in human keratinocytes. The antibacterial and antifungal activities of the formulations were tested while using two gram-negative bacteria (Escherichia coli and Pseudomonas aeruginosa), one gram-positive bacterium (Staphylococcus aureus), and one yeast (Candida albicans).

\section{Materials and Methods}

\subsection{Reagents}

Lipoid S75 (S75), a mixture of soybean phospholipids (70\% phosphatidylcholine, 9\% phosphatidyletanolamine and 3\% lysophosphatidylcholine), triglycerides and fatty acids, was purchased from Lipoid GmbH (Ludwigshafen, Germany). RPMI 1640 medium, DMEM medium, glucose, phosphate-buffered saline (PBS), tryptone water, methylene blue, dimethylsulfoxide (DMSO), and 3-(4,5-dimethylthiazol-2-yl)-2,5-diphenyltetrazolium bromide (MTT) were purchased from Sigma-Aldrich (Madrid, Spain). Mueller-Hinton agar and methanol were purchased from VWR Chemicals (Barcelona, Spain). Mueller-Hinton broth, 2-propanol, and hydrochloric acid 37\% were supplied by Scharlau (Valencia, Spain). Sabouraud Dextrose Chloramphenicol Agar (SDCA) was obtained from Becton Dickinson (Madrid, Spain).

\subsection{Antimicrobial Agents}

Citral, gentamicin sulfate and clotrimazole were purchased from Sigma-Aldrich (Madrid, Spain). Pompia essential oil was extracted from pompia leaves that were collected in 2017 in Siniscola (Sardinia, Italy). $250 \mathrm{~g}$ of leaves were suspended in $700 \mathrm{~mL}$ of water and then subjected to steam distillation while using a Clevenger type apparatus for $2 \mathrm{~h}$ (European Pharmacopoeia 2002, Merk KGaA, Darmstadt, Germany). The yield of essential oil was $0.48 \%(\mathrm{v} / \mathrm{w})$. The extraction was carried out in triplicate, and the obtained essential oils were collected separately, dried over anhydrous sodium sulphate $\left(\mathrm{Na}_{2} \mathrm{SO}_{4}\right)$, and then stored under a nitrogen atmosphere at $4{ }^{\circ} \mathrm{C}$ in amber glass vials until their use and analysis.

\subsection{Gas Chromatography-Mass Spectrometry (GC-MS) Analysis}

The GC analysis of a solution of essential oil in n-hexane was carried out while using an Agilent 7890 GC (Palo Alto, CA, USA) that was equipped with a Gerstel MPS autosampler, coupled with an Agilent 7000C MSD detector as well as to a flame ionization detector (FID). Chromatographic 
separation was performed on a VF-Wax $60 \mathrm{~m} \times 0.25 \mathrm{~mm}$ i.d., $0.5 \mu \mathrm{m}$ film thickness column (Agilent). The following temperature program was used: $40{ }^{\circ} \mathrm{C}$ kept for $4 \mathrm{~min}$., increased to $150{ }^{\circ} \mathrm{C}$ at a rate of $5.0^{\circ} \mathrm{C} / \mathrm{min}$., kept for $3 \mathrm{~min}$. then increased to $240^{\circ} \mathrm{C}$ at a rate of $10^{\circ} \mathrm{C} / \mathrm{min}$, and finally kept for $12 \mathrm{~min}$. Helium was used as the carrier gas at a constant flow of $1.5 \mathrm{~mL} / \mathrm{min}$. The data was analyzed while using a MassHunter Workstation B.06.00 SP1, with identification of the individual components being performed by comparison with the co-injected pure compounds and by matching the MS fragmentation patterns and retention indices with the built-in libraries or literature data or commercial mass spectral libraries (NIST/EPA/NIH 2008; HP1607 purchased from Agilent Technologies (Palo Alto, CA, USA)). The relative percentages of the essential oil constituents were obtained by FID peak area normalization without the use of any correction factor.

\subsection{Vesicle Preparation}

Liposomes were prepared by hydrating S75 $(60 \mathrm{mg} / \mathrm{mL})$ overnight with water, in the presence of pompia essential oil or citral $(20 \mathrm{mg} / \mathrm{mL})$ at room temperature. After complete hydration, the samples were sonicated while using a high ultrasonic disintegrator (Soniprep 150, MSE Crowley, London, UK), three times for 15 cycles ( $5 \mathrm{~s}$ on and $3 \mathrm{~s}$ off; 13 microns of probe amplitude), to obtain small vesicles and homogeneous systems. The vesicle dispersions $(2 \mathrm{~mL})$ were purified from the non-incorporated active components by dialysis against water $(4 \mathrm{~L})$ at $25^{\circ} \mathrm{C}$ for $3 \mathrm{~h}$ (with water refreshed every $30 \mathrm{~min}$.) by using Spectra/Por ${ }^{\circledR}$ membranes (12-14 kDa MW cut-off, $3 \mathrm{~nm}$ pore size; Spectrum Laboratories Inc., DG Breda, the Netherlands) [2,18]. The non-dialysed and dialysed vesicles were diluted with methanol and the amounts of citral or the main components of the pompia essential oil were quantified by gas chromatography, as reported in Section 2.3, to determine entrapment efficiency (EE), which was calculated as the percentage of the active components recovered in the dialysed samples versus the amounts that were found in non-dialysed samples.

\subsection{Vesicle Characterisation}

Transmission electron microscopy (TEM) confirmed vesicle formation and morphology. The samples were stained with 1\% phosphotungstic acid aqueous solution and examined under a JEM-1010 (Jeol Europe, Paris, France) transmission electron microscope, at an accelerating voltage of $80 \mathrm{kV}$, equipped with a digital camera MegaView III and the "AnalySIS" software.

Photon Correlation Spectroscopy determined the average diameter and polydispersity index of the vesicles while using a Zetasizer nano (Malvern Instruments, Worcestershire, UK). The zeta potential of the vesicles was estimated while using the Zetasizer nano by means of the M3-PALS (Phase Analysis Light Scattering) technique. Prior to the analysis, samples $(100 \mu \mathrm{L})$ were diluted with water $(10 \mathrm{~mL})$.

\subsection{In Vitro Biocompatibility}

The biocompatibility of the formulations was evaluated in vitro using immortalized human keratinocytes (HaCaT), which were grown as monolayers in $75 \mathrm{~cm}^{2}$ flasks that were incubated with $100 \%$ humidity and $5 \% \mathrm{CO}_{2}$ at $37^{\circ} \mathrm{C}$. Dulbecco's Modified Eagle Medium (DMEM) with high glucose, $10 \%$ foetal bovine serum, $1 \%$ penicillin/streptomycin, and $0.1 \%$ of fungizone, was used as culture medium. The cells were seeded into 96-well plates and then incubated for $24 \mathrm{~h}$ to reach subconfluence. Afterwards, the cells were treated for $48 \mathrm{~h}$ with citral or pompia essential oil in aqueous dispersion or incorporated in liposomes at different concentrations $(20,2,0.2$, and $0.02 \mu \mathrm{g} / \mathrm{mL}$ of pompia essential oil or citral). At the end of the experiment, the cells were washed with PBS, $100 \mu \mathrm{L}$ of MTT [3(4,5-dimethylthiazolyl-2)-2,5-diphenyltetrazolium bromide] ( $0.5 \mathrm{mg} / \mathrm{mL}$ in PBS, final concentration) was added to each well to measure the percentage of live cells [19,20], and after $3 \mathrm{~h}$, the formed formazan crystals were dissolved with DMSO, and the absorbance was spectrophotometrically read at $570 \mathrm{~nm}$, which is the wavelength of maximum absorption of the formazan crystals, while using a microplate reader (Multiskan EX, Thermo Fisher Scientific, Inc., Walthan, MA, USA). The experiments 
were performed in triplicate and repeated at least three times. The results are shown as a percentage of cell viability in comparison to untreated cells ( $100 \%$ viability).

\subsection{Microbial Strains}

The antibacterial activity of pompia essential oil and citral, both in aqueous dispersion and loaded in liposomes, was tested against two gram-negative bacteria (Escherichia coli CECT 516 and Pseudomonas aeruginosa CECT 111), one gram-positive bacterium (Staphylococcus aureus CECT 239), and a yeast (Candida albicans CECT 1394). The cultures were kept at $36^{\circ} \mathrm{C} \pm 1$ for $24 \mathrm{~h}$. After $24 \mathrm{~h}$ of incubation, the bacterial and fungal suspensions were diluted with tryptone water to obtain an adequate density expressed as colony forming units per milliliter (CFU/mL).

\subsection{Antimicrobial Tests}

The antimicrobial activity of pompia essential oil and citral was evaluated while using both agar diffusion and microdilution tests, as described below.

\subsubsection{Agar Diffusion Method}

Bacterial and fungal inocula were uniformly spread on the surface of a sterile Petri dish containing Mueller-Hinton agar while using sterile cotton swab. In the case of C. albicans, $2 \%$ of glucose and $0.5 \mu \mathrm{g} / \mathrm{mL}$ of methylene blue were added to the Mueller-Hinton agar. The addition of glucose provides better yeast growth, and methylene blue increases the definition of inhibition halos. Both of the supplements were incorporated during the preparation of the medium prior to sterilization. The density of the bacteria inoculum (E. coli, P. aeruginosa and S. aureus) was $1.4 \times 10^{8} \mathrm{CFU} / \mathrm{mL}$. In the case of C. albicans, the inoculum used was $6 \times 10^{6} \mathrm{CFU} / \mathrm{mL}$.

The paper discs were impregnated with $20 \mu \mathrm{L}$ of each sample: pompia essential oil or citral solubilized in DMSO $(300 \mathrm{mg} / \mathrm{mL})$. The impregnated discs were placed onto the surface of the agar. The controls used were different as a function of the microorganism considered: gentamicin sulphate $(1500 \mu \mathrm{g} / \mathrm{mL}$ in water) for bacterial strains and clotrimazole $(250 \mu \mathrm{g} / \mathrm{mL}$ in methanol) for C. albicans. The plates were incubated at $36^{\circ} \mathrm{C} \pm 1{ }^{\circ} \mathrm{C}$ for $24 \mathrm{~h}$, under aerobic conditions, and the diameter of the inhibition halo was measured in $\mathrm{mm}$.

\subsubsection{Micro-Dilution Method}

The broth micro-dilution method was applied while using 96-well microtitration plates and Eppendorf tubes. Microtitration plates and Eppendorf tubes were incubated at $35{ }^{\circ} \mathrm{C}$ for $24 \mathrm{~h}$. Turbidity was measured in the case of microtitration plates, while MTT (3(4,5-dimethylthiazolyl-2)-2,5-diphenyltetrazolium bromide) was added to the Eppendorf tubes to colorimetrically determine the viable microorganisms.

\section{A. Turbidimetric Assay}

Microorganisms were seeded in microtitration plates and treated with pompia essential oil and citral at different concentrations $(0.75,1.5,3,6$, and $12 \mathrm{mg} / \mathrm{mL})$. Pompia essential oil and citral were first dissolved in DMSO (300 mg/mL) and subsequently diluted with Mueller-Hinton broth (for bacteria) or RPMI medium containing $2 \%$ glucose (for yeast) to obtain the desired concentrations.

In the case of the bacteria (E. coli, P. aeruginosa and S. aureus), the final inoculum concentration in the wells was approximately $5 \times 10^{5} \mathrm{CFU} / \mathrm{mL}$, while, in the case of $C$. albicans, the density of the inoculum was approximately $2 \times 10^{5} \mathrm{CFU} / \mathrm{mL}$. The 96 -well plates were incubated at $35^{\circ} \mathrm{C}$ for $24 \mathrm{~h}$, and the turbidity in each well was measured with a spectrophotometer $(\lambda=530 \mathrm{~nm})$ and compared with that obtained in the positive growth control wells (with inoculum and without the assayed substances) to determine the minimum concentrations of pompia essential oil and citral that are required to inhibit the growth of microorganisms by $50 \%\left(\mathrm{MIC}_{50}\right)$. 
The minimum bactericidal concentration (MBC) or the minimum fungicidal concentration (MFC) were evaluated by spreading an aliquot (approx. $20 \mu \mathrm{L}$ ) of the content of each well on the surface of a Petri dish containing Mueller-Hinton agar in the case of bacteria (E. coli, P. aeruginosa and S. aureus) and SDCA for C. albicans, and measuring the lowest concentration of the samples with no growth of the tested microorganism after $24 \mathrm{~h}$ (bacteria) or $48 \mathrm{~h}$ (C. albicans) of incubation at $35^{\circ} \mathrm{C}$.

\section{B. Colorimetric Assay}

The $\mathrm{MIC}_{50}$ values for pompia essential oil and citral loaded liposomes were determined by means of a colorimetric method, as the standard turbidity test could not be used due to the self-turbidity of the liposomes. Briefly, liposomes that were diluted with Mueller-Hinton broth (for bacteria) or RPMI medium with $2 \%$ glucose (for yeast) were inoculated with the corresponding microorganism, while using the same volumes and inoculum concentrations that were described for the turbidimetric assay. Pompia essential oil and citral loaded liposomes were used at different concentrations: 0.15 , $0.30,0.60,1.20,2.50,5$, and $10 \mathrm{mg} / \mathrm{mL}$. The Eppendorf tubes were incubated at $35{ }^{\circ} \mathrm{C}$ for $24 \mathrm{~h}$, and at the end of the experiment $10 \mu \mathrm{L}$ of MTT $\left(5 \mathrm{mg} / \mathrm{mL}\right.$ in $\left.\mathrm{H}_{2} \mathrm{O}\right)$ were added to each tube. The tubes were incubated for an additional time period of $45 \mathrm{~min}$. (bacteria) or $4 \mathrm{~h}$ (yeast). $1 \mathrm{~mL}$ of acidic isopropanol solution $(0.4 \%(\mathrm{v} / \mathrm{v})$ hydrochloric acid in isopropanol) was added to each tube to stop the MTT reduction by the microorganisms. The dispersions were centrifuged $(8000 \times g, 3 \mathrm{~min}$.) and the absorbance of the supernatant was measured at $570 \mathrm{~nm}$, which is the wavelength of maximum absorption of the formazan crystals, while using a spectrophotometer (Multiskan EX, Thermo Fisher Scientific, Inc., Waltham, MA, USA) and compared with that obtained for positive growth control tubes (with inoculum and without liposomes) to determine the percentage of growth inhibition $\left(\mathrm{MIC}_{50}\right)$.

\subsection{Statistical Data Analysis}

The results are expressed as means \pm standard deviations. Multiple comparisons of means (ANOVA) were used to substantiate statistical differences between groups, while the Student's t-test was used to compare two samples. Significance was tested at the 0.05 level of probability $(p<0.05)$. Data analysis was carried out with the XLStatistics software package for Excel [21].

\section{Results}

\subsection{Essential Oil Characterisation}

The phytochemical characterisation of pompia essential oil was carried out by liquid injection in a gas chromatographic device. Table 1 reports the main components of the essential oil and their relative percentages.

Table 1. Main compounds detected in the essential oil from pompia leaves.

\begin{tabular}{|c|c|c|c|}
\hline Compound & RT & $\mathbf{A} \%$ & RI \\
\hline$\alpha$-Pinene & 13.37 & 0.4 & 1033 \\
\hline Camphene & 14.85 & $\operatorname{tr}$ & 1081 \\
\hline$\beta$-Pinene & 16.26 & 1.1 & 1126 \\
\hline Sabinene & 16.67 & 0.4 & 1139 \\
\hline 3-carene & 17.59 & 0.9 & 1166 \\
\hline$\beta$-Myrcene & 17.87 & 0.8 & 1175 \\
\hline 2,3-Dehydro-1,8-cineole & 18.89 & $\operatorname{tr}$ & 1206 \\
\hline limonene & 19.24 & 29.7 & 1217 \\
\hline$\beta$-Z-Ocimene & 20.26 & 0.5 & 1249 \\
\hline$\beta$-E-Ocimene & 20.83 & 4.4 & 1267 \\
\hline
\end{tabular}


Table 1. Cont.

\begin{tabular}{lccc}
\hline \multicolumn{1}{c}{ Compound } & RT & A $\%$ & RI \\
\hline p-Cymene & 21.55 & 0.7 & 1290 \\
Terpinolene & 21.99 & tr & 1304 \\
5-Hepten-2-one, 6-methyl- & 23.43 & 0.9 & 1352 \\
cis-Linalool oxide & 26.27 & 0.1 & 1448 \\
trans-Linalool oxide (furanoid) & 27.05 & 0.0 & 1475 \\
Citronellal & 27.32 & 0.2 & 1484 \\
Linalool & 28.87 & 11.0 & 1535 \\
Linalyl acetate & 29.46 & 20.9 & 1555 \\
3-Methoxy-p-cymene & 30.73 & 0.2 & 1596 \\
Terpinen-4-ol & 31.07 & 0.3 & 1609 \\
Megastigma-triene (not identified isomer) & 31.40 & 0.7 & 1622 \\
Neral & 33.07 & 6.8 & 1689 \\
$\alpha$-Terpineol & 33.17 & 2.2 & 1693 \\
Neryl acetate & 33.72 & 1.1 & 1718 \\
Geranial & 34.06 & 11.1 & 1735 \\
Nerol & 34.29 & 2.9 & 1746 \\
cis-geraniol & 35.00 & 0.5 & 1780 \\
Geraniol & 35.74 & 1.2 & 1819 \\
Unknown & 38.48 & 0.3 & 1985 \\
Unknown & 38.59 & 0.2 & 1992 \\
Unknown & 40.12 & 0.2 & 2090 \\
Menthadien-1,2-diol & 41.87 & 0.1 & 2216 \\
Neric acid & 42.90 & 0.2 & 2286 \\
\hline
\end{tabular}

RT: retention time. RI: experimental retention indices calculated on a VF-Wax $60 \mathrm{~m}$ column; tr: trace. The results are expressed as relative percent area obtained by internal normalisation of FID chromatograms.

Limonene, lilalyl acetate, geranial, (E)- $\beta$-ocimene, linalool, and citral were the main components of the essential oil. Citral (the sum of geranial and neral) represents $17.9 \%$ of the essential oil and it is considered to be mainly responsible for the antimicrobial properties of the pompia essential oil [3].

\subsection{Vesicle Preparation and Characterisation}

The essential oil extracted from pompia leaves was loaded in liposomes, given that essential oils loaded liposomes are promising agents that can be used to increase the antimicrobial activity of essential oils [22]. The formulations were observed under TEM to confirm the formation of the vesicles and evaluate their structure and size (Figure 1). This technique was chosen, because the structure of soft matters is well preserved upon staining, avoiding artefacts and showing the real shape of the system.

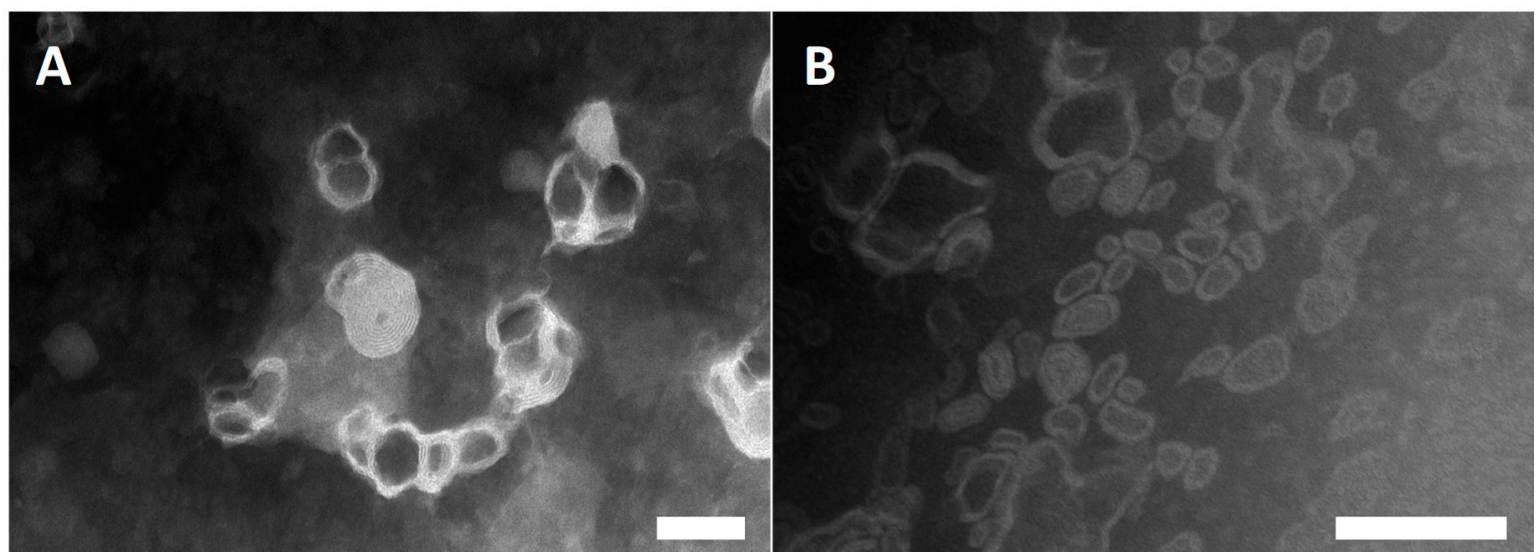

Figure 1. Transmission electron microscopy (TEM) images of pompia essential oil liposomes (A) and citral liposomes (B). Bars correspond to $100 \mathrm{~nm}$. 
The vesicles were small in size, irregularly shaped, and slightly aggregated.

Citral loaded liposomes were prepared as a reference. The empty liposomes were also prepared, in order to evaluate the effect of pompia essential oil and citral on the vesicle assembly. The empty vesicles were smaller $(\sim 75 \mathrm{~nm})$ than vesicles loading pompia essential oil or citral ( 152 and $129 \mathrm{~nm}$, respectively), as reported in Table 2.

Table 2. Mean diameter (MD), polydispersity index (PI), zeta potential (ZP), and entrapment efficiency (EE) of empty, pompia essential oil-, and citral loaded liposomes. Mean values \pm standard deviations were obtained from at least six replicates.

\begin{tabular}{lcccc}
\hline & MD (nm) & PI & ZP (mV) & EE (\%) \\
\hline Empty liposomes & $75 \pm 4$ & $0.28 \pm 0.02$ & $-70 \pm 2$ & - \\
Pompia e.o. loaded liposomes & $152 \pm 18$ & $0.31 \pm 0.05$ & $-74 \pm 5$ & $85 \pm 15$ \\
Citral loaded liposomes & $129 \pm 16$ & $0.32 \pm 0.05$ & $-72 \pm 4$ & $88 \pm 13$ \\
\hline
\end{tabular}

The incorporation of the essential oil or citral in liposomes led to a slight decrease in the homogeneity of the systems, as the polydispesity index increased from 0.28 to 0.31 (for pompia e.o. loaded liposomes) or 0.32 (for citral loaded liposomes). The formulations were reproducible and repeatable, despite the increase in size [23]. All of the vesicles were highly negatively charged, which is predictive of good stability on storage. Additionally, the incorporation of the payloads did not modify the surface charge of liposomes as compared to empty liposomes, thus confirming the localisation of the active compounds within the bilayer, as previously reported [24]. The amount of pompia essential oil and citral incorporated in the vesicles was very high (entrapment efficiency was around $86 \%$ ), thus confirming the results of other authors [24].

\subsection{In Vitro Biocompatibility Studies in Keratinocytes}

The biocompatibility of the formulations was evaluated by incubating keratinocytes with the prepared samples for $48 \mathrm{~h}$. The dispersions of pompia essential oil or citral in water were used as references (Figure 2).

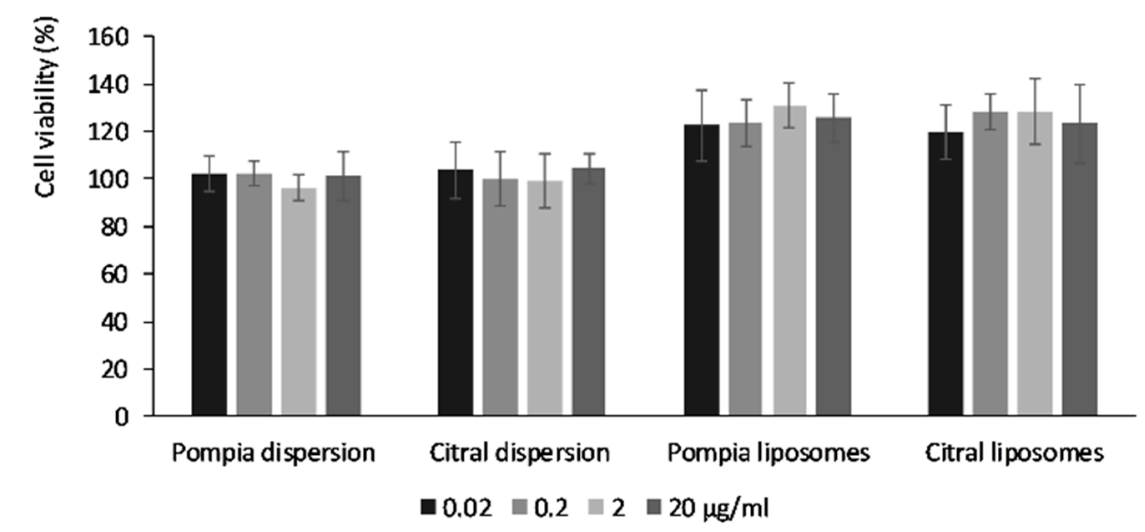

Figure 2. Cell viability of keratinocytes incubated for $48 \mathrm{~h}$ with pompia essential oil or citral loaded liposomes or the aqueous dispersions. Data are reported as mean values \pm standard deviations of cell viability expressed as the percentage of control (100\% of viability).

All of the formulations were highly biocompatible, as the cell viability was always above $100 \%$. In addition, the incorporation of the essential oil or citral in the vesicles induced cell proliferation, with an increase in viability of $\sim 20-30 \%$ in comparison with the untreated control cells ( $100 \%$ viability). 


\subsection{Agar Diffusion Method}

The first screening was carried out by evaluating the efficacy of raw essential oil and citral against E. coli, P. aeruginosa, S. aureus, and C. albicans. The activity was compared with that of gentamicin and clotrimazole. The growth of E. coli, S. aureus, and C. albicans was inhibited by pompia essential oil and citral solutions ( $300 \mathrm{mg} / \mathrm{mL}$ in DMSO), confirming their ability to inhibit bacteria proliferation, as previously reported for pompia essential oil [3] and citral [5,25]. Very low inhibition halos were observed in the plates containing P. aeruginosa (Table 3).

Table 3. Inhibition halo $(\mathrm{IH})$ provided by pompia essential oil, citral, gentamicin and clotrimazole against E. coli, P. aeruginosa, S. aureus, and C. albicans. Mean values \pm standard deviations $(\mathrm{n}=4)$ are reported.

\begin{tabular}{lcccc}
\hline \multicolumn{1}{c}{$\begin{array}{c}\text { Compound } \\
\text { (concentration) }\end{array}$} & E. coli $\mathbf{I H}(\mathbf{m m})$ & P. aeruginosa $\mathbf{I H}(\mathbf{m m})$ & S. aureus $\mathbf{I H}(\mathbf{m m})$ & C. albicans IH (mm) \\
\hline Pompia e.o. $(300 \mathrm{mg} / \mathrm{mL})$ & $13 \pm 2$ & $<5$ & $25 \pm 6$ & $16 \pm 3$ \\
Citral $(300 \mathrm{mg} / \mathrm{mL})$ & $20 \pm 4$ & $<5$ & $37 \pm 1$ & $25 \pm 5$ \\
Gentamicin $(1.5 \mathrm{mg} / \mathrm{mL})$ & $22 \pm 4$ & $24 \pm 2$ & $27 \pm 2$ & - \\
Clotrimazole $(250 \mu \mathrm{g} / \mathrm{mL})$ & - & - & - & $25 \pm 1$ \\
\hline
\end{tabular}

Citral was more effective against E. coli, S. aureus, and C. albicans, and gave larger inhibition halos in comparison with that provided by pompia essential oil (Table 3). However, a dose of essential oil or citral 20 times higher had to be used $(300 \mathrm{mg} / \mathrm{mL})$ to reach an inhibition halo similar to that of gentamicin or clotrimazole.

\subsection{Micro-Dilution Method}

The $\mathrm{MIC}_{50}$ or MFC/MBC of pompia essential oil and citral solutions were measured while using the micro-dilution method (Table 4) [26].

Table 4. Values of $\mathrm{MIC}_{50}$ (minimum inhibitory concentration 50\%) and MFC (minimum fungicidal concentration) or MBC (minimum bactericidal concentration) of pompia essential oil and citral in solution or loaded in liposomes. Results are expressed in $\mathrm{mg}$ of active ingredient per $\mathrm{mL}$ of final volume.

\begin{tabular}{lcc}
\hline & MIC $_{\mathbf{5 0}}(\mathbf{m g} / \mathbf{m L})$ & MFC or MBC \\
\hline E. coli & 3 & 12 \\
\hline Pompia e.o. & 10 & $>10$ \\
Pompia e.o. loaded liposomes & 1.5 & 6 \\
Citral & 5 & 10 \\
Citral loaded liposomes & & \\
\hline P. aeruginosa & 6 & 12 \\
\hline Pompia e.o. & 5 & 10 \\
Pompia e.o. loaded liposomes & 6 & $>12$ \\
Citral & 5 & 10 \\
Citral loaded liposomes & & 6 \\
\hline S. aureus & 3 & 3 \\
\hline Pompia e.o. & 10 & 5 \\
Pompia e.o. loaded liposomes & 1.5 & \\
Citral & 5 & 6 \\
Citral loaded liposomes & & 3 \\
\hline C. albicans & 3 & 2.5 \\
\hline Pompia e.o. & 2.5 & \\
Pompia e.o. loaded liposomes & 1.5 & \\
Citral & 0.6 & \\
Citral loaded liposomes & & \\
\hline
\end{tabular}


The essential oil and citral showed comparable antimicrobial activities, although citral was slightly more effective (lower $\mathrm{MIC}_{50}$ and $\mathrm{MFC} / \mathrm{MBC}$ ) against E. coli, S. aureus and C. albicans. The antimicrobial results that were obtained while using liposomes were also similar, with citral loaded liposomes being more active than pompia liposomes against E. coli, S. aureus and C. albicans.

Unfortunately, it was not possible to measure the $\mathrm{MIC}_{50}$ and the MFC or MBC of pompia essential oil and citral when they were loaded in liposomes due the turbidity that was caused by liposome dispersions that altered the ABS values. For this reason, the ABS values were measured by means of a colorimetric assay [26].

The $\mathrm{MIC}_{50}$ and $\mathrm{MBC}$ against $P$. aeruginosa obtained while using pompia essential oil and citral in solution or loaded in liposomes were the same. Against E. coli and S. aureus, the pompia essential oil and citral solutions seemed to be active at concentrations lower than those that were found for the liposomes. The $\mathrm{MIC}_{50}$ against $\mathrm{C}$. albicans obtained while using the essential oil in solution or loaded in liposomes were similar, while, in the case of citral loaded liposomes, the values were lower than those found for the citral solution, which points to the ability of liposomes to promote the delivery of citral. However, the MFC values were similar for both samples. These results suggest that the incorporation of citral in liposomes promotes the antifungal activity against C. albicans.

\section{Discussion}

The use of natural compounds as a safe and effective alternative to synthetic antimicrobials is mainly related to the large number of resistant strains to a wide variety of chemicals [27]. In particular, whole extracts from plants often provide greater in vitro and/or in vivo antimicrobial activity than the isolated constituents at an equivalent dose [28]. The antimicrobial activity of phytocomplexes can be attributed to a combination of complementary activities of different components [29]. Essential oils are complex mixtures of lipophilic, liquid, volatile, and often terpenoid compounds that are present in higher plants. Monoterpenes (hydrocarbon and oxygenated monoterpens), sesquiterpenes (hydrocarbon and oxygenated sesquiterpens), and, furthermore, phenolic compounds are mainly present [30]. Thanks to their chemical composition, essential oils possess antioxidant, anti-inflammatory, and antimicrobial activities [31]. Their antimicrobial activity is due to their ability to penetrate and interfere with the pathogen membrane, altering its structure and functionality, or interfering with the functionality of wall proteins that are involved in the processes of transport of compounds. Additionally, terpenoids have been found to interfere with the enzymatic reactions of energy metabolism [32,33].

Despite their high lipophilicity, the volatile components of essential oils are easily subjected to degradation, which is responsible for their reduced therapeutic effect. Additionally, essential oils display low in vivo bioavailability, due to their lipophilic nature [34,35].

Pompia essential oil was incorporated in liposomes in this study to prevent degradation and improve bioavailability. Liposomes that were loaded with citral, one of the main components of Citrus essential oils, were also prepared. Liposomes were prepared by direct sonication, avoiding the use of organic solvents and dissipative steps [36], according to the principles of Green Chemistry and ensuring the sustainability of the formulations [37]. The prepared vesicles were fairly spherical in shape, small in size, and able to incorporate high amounts of essential oil and citral. In addition, liposomes were highly biocompatible, as demonstrated by the in vitro studies that were carried out while using human keratinocytes. The ability of liposomes to improve the delivery of small and large molecules to the skin is well known [38,39]. Recently, they have been successfully proposed for the skin delivery of phytochemicals due to their high loading and carrier capabilities, as well as affinity with the skin [40]. The ability to potentiate the efficacy of essential oils was also demonstrated [41]. In previous studies, the optimal skin delivery performance of the phospholipid vesicles in the delivery of Santolina insularis essential oil were demonstrated [23]. Additionally, new biocarriers, called santosomes, were formulated by combining Santolina insularis essential oil and hydrogenated phosphatidylcholine. These vesicles were able to promote the skin delivery of phycocyanin, a cyanobacteria protein, thanks to the synergistic activity of the terpenes that are present in the essential oil and phospholipid [42]. 
Taking the recognized capabilities of liposomes into account to improve the dermal delivery of essential oils, in this study we focused on the evaluation of the antibacterial activity of liposomes that were loaded with pompia essential oil. The agar diffusion assay confirmed the antimicrobial activity of the oil against E. coli, S. aureus, C. albicans, and P. aeruginosa (Table 3); this being the first screening of antibacterial activity against different pathogens [43]. However, since microdilution and colorimetric assays are more accurate methods for the evaluation of the antibacterial activity of chemicals, they were also performed. These tests showed that pompia essential oil and citral were both active against all of the assayed pathogens and the incorporation in liposomes affected their inhibitory power differently (Table 4). The liposome formulations provided an increase of $\mathrm{MIC}_{50}$ and $\mathrm{MBC}$ against E. coli and $S$. aureus, but they did not modify the efficacy against P. aeruginosa and promoted the antifungal efficacy of citral against $C$. albicans. The obtained results confirm that citral is one of the most potent antibacterial components of pompia essential oil, and its incorporation in liposomes improves its antifungal activity.

\section{Conclusions}

The overall results suggest that pompia essential oil and citral can be suitably loaded in liposomes, thus facilitating their dermal delivery and interaction with epidermal cells. Subsequently, liposomes are able to increase the concentration of bioactive molecules in the infected target tissue and promote their efficacy. Citral loaded liposomes are more effective than pompia essential oil liposomes in counteracting the growth of bacteria (E. coli and S. aureus) and fungi (C. albicans).

Author Contributions: Conceptualization, M.L.M., M.M. and C.C.; methodology, J.-E.P., I.U. and G.L.P.; formal analysis, I.U., M.A., G.L.P. and E.M.; investigation, M.L.M., C.C. and I.U.; data curation, M.L.M. and C.C., writing—original draft preparation, M.M., M.L.M. and C.C.; writing—review and editing, M.L.M., C.C. and M.M.; supervision, M.M. and J.-E.P. All authors have read and agreed to the published version of the manuscript.

Funding: This research received no external funding.

Conflicts of Interest: The authors declare no conflict of interest.

\section{References}

1. Camarda, I.; Mazzola, P.; Brunu, A.; Fenu, G.; Lombardo, G.; Palla, F. Un Agrume Nella Storia Della Sardegna: Citrus Limon Var. Pompia Camarda Var. Nova. Quad. Bot. Amb. Appl. 2013, 24, 109-118.

2. Manconi, M.; Manca, M.L.; Marongiu, F.; Caddeo, C.; Castangia, I.; Petretto, G.L.; Pintore, G.; Sarais, G.; D’hallewin, G.; Zaru, M.; et al. Chemical Characterization of Citrus Limon Var. Pompia and Incorporation in Phospholipid Vesicles for Skin Delivery. Int. J. Pharm. 2016, 506, 449-457. [CrossRef] [PubMed]

3. Fancello, F.; Petretto, G.L.; Zara, S.; Sanna, M.L.; Addis, R.; Maldini, M.; Foddai, M.; Rourke, J.P.; Chessa, M.; Pintore, G. Chemical Characterization, Antioxidant Capacity and Antimicrobial Activity Against Food Related Microorganisms of Citrus Limon Var. Pompia Leaf Essential Oil. LWT-Food Sci. Technol. 2016, 69, 579-585. [CrossRef]

4. Fraternale, D.; Giamperi, L.; Bucchini, A.; Cara, P.; Ricci, D. In Vitro Plant Regeneration from Callus of Citrus X Monstruosa (Pompia), an Endemic Citrus of Sardinia. Nat. Prod. Commun. 2010, 5, 927-930. [CrossRef] [PubMed]

5. Saddiq, A.A.; Khayyat, S.A. Chemical and Antimicrobial Studies of Monoterpene: Citral. Pestic. Biochem. Physiol. 2010, 98, 89-93. [CrossRef]

6. Martins, A.P.; Salgueiro, L.; Goncalves, M.J.; da Cunha, A.P.; Vila, R.; Canigueral, S.; Mazzoni, V.; Tomi, F.; Casanova, J. Essential Oil Composition and Antimicrobial Activity of Three Zingiberaceae from S. Tome E Principe. Planta Med. 2001, 67, 580-584. [CrossRef]

7. Zhang, Y.; Wei, J.; Chen, H.; Song, Z.; Guo, H.; Yuan, Y.; Yue, T. Antibacterial Activity of Essential Oils Against Stenotrophomonas Maltophilia and the Effect of Citral on Cell Membrane. LWT 2020, 117, 108667. [CrossRef]

8. Hu, L.; Du, M.; Zhang, J.; Wang, Y. Chemistry of the Main Component of Essential Oil of Litsea Cubeba and its Derivatives. Open J. For. 2014, 4, 457-466.

9. Hu, W.; Li, C.; Dai, J.; Cui, H.; Lin, L. Antibacterial Activity and Mechanism of Litsea Cubeba Essential Oil Against Methicillin-Resistant Staphylococcus Aureus (MRSA). Ind. Crops Prod. 2019, 130, 34-41. [CrossRef] 
10. Turek, C.; Stintzing, F.C. Stability of Essential Oils: A Review. Compr. Rev. Food Sci. Food Saf. 2013, 12, 40-53. [CrossRef]

11. Koning, G.A.; Storm, G. Targeted Drug Delivery Systems for the Intracellular Delivery of Macromolecular Drugs. Drug Discov. Today 2003, 8, 482-483. [CrossRef]

12. Metselaar, J.M.; Storm, G. Liposomes in the Treatment of Inflammatory Disorders. Expert. Opin. Drug Deliv. 2005, 2, 465-476. [CrossRef] [PubMed]

13. Ding, B.S.; Dziubla, T.; Shuvaev, V.V.; Muro, S.; Muzykantov, V.R. Advanced Drug Delivery Systems that Target the Vascular Endothelium. Mol. Interv. 2006, 6, 98-112. [CrossRef] [PubMed]

14. Hua, S.; Wu, S.Y. The use of Lipid-Based Nanocarriers for Targeted Pain Therapies. Front. Pharmacol. 2013, 4, 143. [CrossRef]

15. Cui, H.; Li, W.; Li, C.; Vittayapadung, S.; Lin, L. Liposome Containing Cinnamon Oil with Antibacterial Activity Against Methicillin-Resistant Staphylococcus Aureus Biofilm. Biofouling 2016, 32, 215-225. [CrossRef]

16. Manconi, M.; Petretto, G.; D’hallewin, G.; Escribano, E.; Milia, E.; Pinna, R.; Palmieri, A.; Firoznezhad, M.; Peris, J.E.; Usach, I.; et al. Thymus Essential Oil Extraction, Characterization and Incorporation in Phospholipid Vesicles for the Antioxidant/Antibacterial Treatment of Oral Cavity Diseases. Colloids Surf. B Biointerfaces 2018, 171, 115-122. [CrossRef]

17. Risaliti, L.; Kehagia, A.; Daoultzi, E.; Lazari, D.; Bergonzi, M.C.; Vergkizi-Nikolakaki, S.; Hadjipavlou-Litina, D.; Bilia, A.R. Liposomes Loaded with Salvia Triloba and Rosmarinus Officinalis Essential Oils: In Vitro Assessment of Antioxidant, Antiinflammatory and Antibacterial Activities. J. Drug Deliv. Sci. Technol. 2019, 51, 493-498. [CrossRef]

18. Castangia, I.; Caddeo, C.; Manca, M.L.; Casu, L.; Latorre, A.C.; Diez-Sales, O.; Ruiz-Sauri, A.; Bacchetta, G.; Fadda, A.M.; Manconi, M. Delivery of Liquorice Extract by Liposomes and Hyalurosomes to Protect the Skin Against Oxidative Stress Injuries. Carbohydr. Polym. 2015, 134, 657-663. [CrossRef]

19. Manca, M.L.; Castangia, I.; Zaru, M.; Nacher, A.; Valenti, D.; Fernandez-Busquets, X.; Fadda, A.M.; Manconi, M. Development of Curcumin Loaded Sodium Hyaluronate Immobilized Vesicles (Hyalurosomes) and their Potential on Skin Inflammation and Wound Restoring. Biomaterials 2015, 71, 100-109. [CrossRef]

20. Manca, M.L.; Manconi, M.; Falchi, A.M.; Castangia, I.; Valenti, D.; Lampis, S.; Fadda, A.M. Close-Packed Vesicles for Diclofenac Skin Delivery and Fibroblast Targeting. Colloids Surf. B Biointerfaces 2013, 111, 609-617. [CrossRef]

21. Ihaka, R.; Gentleman, R. R: A Language for Data Analysis and Graphics. J. Comput. Gr. Stat. 1996, 5, $299-314$.

22. Sherry, M.; Charcosset, C.; Fessi, H.; Greige-Gerges, H. Essential Oils Encapsulated in Liposomes: A Review. J. Liposome Res. 2013, 23, 268-275. [CrossRef] [PubMed]

23. Castangia, I.; Manca, M.L.; Caddeo, C.; Maxia, A.; Murgia, S.; Pons, R.; Demurtas, D.; Pando, D.; Falconieri, D.; Peris, J.E. Faceted Phospholipid Vesicles Tailored for the Delivery of Santolina Insularis Essential Oil to the Skin. Colloids Surf. B Biointerfaces 2015, 132, 185-193. [CrossRef] [PubMed]

24. Wen, Z.; Liu, B.; Zheng, Z.; You, X.; Pu, Y.; Li, Q. Preparation of Liposomes Entrapping Essential Oil from Atractylodes Macrocephala Koidz by Modified RESS Technique. Chem. Eng. Res. Des. 2010, 88, 1102-1107. [CrossRef]

25. Espina, L.; Berdejo, D.; Alfonso, P.; García-Gonzalo, D.; Pagán, R. Potential use of Carvacrol and Citral to Inactivate Biofilm Cells and Eliminate Biofouling. Food Control 2017, 82, 256-265. [CrossRef]

26. Balouiri, M.; Sadiki, M.; Ibnsouda, S.K. Methods for in Vitro Evaluating Antimicrobial Activity: A Review. J. Pharm. Anal. 2016, 6, 71-79. [CrossRef] [PubMed]

27. Rossiter, S.E.; Fletcher, M.H.; Wuest, W.M. Natural Products as Platforms to Overcome Antibiotic Resistance. Chem. Rev. 2017, 117, 12415-12474. [CrossRef]

28. Rasoanaivo, P.; Wright, C.W.; Willcox, M.L.; Gilbert, B. Whole Plant Extracts Versus Single Compounds for the Treatment of Malaria: Synergy and Positive Interactions. Malar. J. 2011, 10, S4. [CrossRef]

29. Cheesman, M.J.; Ilanko, A.; Blonk, B.; Cock, I.E. Developing New Antimicrobial Therapies: Are Synergistic Combinations of Plant Extracts/Compounds with Conventional Antibiotics the Solution? Pharmacogn. Rev. 2017, 11, 57-72.

30. Kohlert, C.; van Rensen, I.; Marz, R.; Schindler, G.; Graefe, E.U.; Veit, M. Bioavailability and Pharmacokinetics of Natural Volatile Terpenes in Animals and Humans. Planta Med. 2000, 66, 495-505. [CrossRef]

31. Dhifi, W.; Bellili, S.; Jazi, S.; Bahloul, N.; Mnif, W. Essential Oils' Chemical Characterization and Investigation of some Biological Activities: A Critical Review. Medicines 2016, 3, 25. [CrossRef] [PubMed] 
32. Sikkema, J.; de Bont, J.A.; Poolman, B. Mechanisms of Membrane Toxicity of Hydrocarbons. Microbiol. Rev. 1995, 59, 201-222. [CrossRef] [PubMed]

33. Knobloch, K.; Pauli, A.; Iberl, B.; Weigand, H.; Weis, N. Antibacterial and Antifungal Properties of Essential Oil Components. J. Essent. Oil Res. 1989, 1, 119-128. [CrossRef]

34. Wu, G.; Zhang, X.; Li, F. Advances in Pharmaceutical Studies on Improvement of Stability of Volatile Oils of Chinese Materia Medica. Pharm. Care Res. 2008, 8, 197-200.

35. Zhao, Y.; Wang, C.; Chow, A.H.; Ren, K.; Gong, T.; Zhang, Z.; Zheng, Y. Self-Nanoemulsifying Drug Delivery System (SNEDDS) for Oral Delivery of Zedoary Essential Oil: Formulation and Bioavailability Studies. Int. J. Pharm. 2010, 383, 170-177. [CrossRef] [PubMed]

36. Manconi, M.; Aparicio, J.; Vila, A.O.; Pendás, J.; Figueruelo, J.; Molina, F. Viscoelastic Properties of Concentrated Dispersions in Water of Soy Lecithin. Colloids Surf. A Physicochem. Eng. Asp. 2003, 222, 141-145. [CrossRef]

37. De Matos, S.P.; Teixeira, H.F.; De Lima, A.A.N.; Veiga-Junior, V.F.; Koester, L.S. Essential Oils and Isolated Terpenes in Nanosystems Designed for Topical Administration: A Review. Biomolecules 2019, 9, 138. [CrossRef]

38. Egbaria, K.; Weiner, N. Liposomes as a Topical Drug Delivery System. Adv. Drug Deliv. Rev. 1990, 5, $287-300$. [CrossRef]

39. Manconi, M.; Pendas, J.; Ledon, N.; Moreira, T.; Sinico, C.; Saso, L.; Fadda, A.M. Phycocyanin Liposomes for Topical Anti-Inflammatory Activity: In-Vitro in-Vivo Studies. J. Pharm. Pharmacol. 2009, 61, 423-430. [CrossRef]

40. Singh, M.; Devi, S.; Rana, V.S.; Mishra, B.B.; Kumar, J.; Ahluwalia, V. Delivery of Phytochemicals by Liposome Cargos: Recent Progress, Challenges and Opportunities. J. Microencapsul. 2019, 36, 215-235. [CrossRef]

41. Hammoud, Z.; Gharib, R.; Fourmentin, S.; Elaissari, A.; Greige-Gerges, H. New Findings on the Incorporation of Essential Oil Components into Liposomes Composed of Lipoid S100 and Cholesterol. Int. J. Pharm. 2019, 561, 161-170. [CrossRef] [PubMed]

42. Castangia, I.; Manca, M.L.; Caddeo, C.; Bacchetta, G.; Pons, R.; Demurtas, D.; Diez-Sales, O.; Fadda, A.M.; Manconi, M. Santosomes as Natural and Efficient Carriers for the Improvement of Phycocyanin Reepithelising Ability in Vitro and in Vivo. Eur. J. Pharm. Biopharm. 2016, 103, 149-158. [CrossRef] [PubMed]

43. Ezzeddine, N.B.; Abdelkéfi, M.M.; Aissa, R.B.; Chaabouni, M.M. Antibacterial Screening of Origanum Majorana L. Oil from Tunisia. J. Essent. Oil Res. 2001, 13, 295-297. [CrossRef] 